\title{
New proposal for the serum ascites albumin gradient cut-off value in Chinese ascitic patients
}

\author{
Cai-feng Jiang ${ }^{\dagger}$, Bin Shi ${ }^{\dagger}$, Jian Shi, Zong-li Yuan and Wei-fen Xie
}

\begin{abstract}
Background: Serum ascites albumin gradient (SAAG) has been recognized as a reliable marker in the differential diagnosis of ascites. The etiological background of cirrhosis is rather different between western countries and eastern countries. The threshold of SAAG in Chinese ascitic patients has not been evaluated yet. The aim of this study was to define a new reasonable threshold of SAAG in Chinese ascitic patients.

Methods: Adult patients with ascites admitted to the Shanghai Changzheng Hospital from Jan 2004 to Jun 2010 were retrospectively analyzed. The diagnostic criteria for cirrhotic ascites are clinical manifestations, radiological features and esophageal-gastric varicosis, or histopathology. Serum was detected by chemical method using a commercial kit. We used receiver operating characteristic (ROC) analysis to achieve maximal sensitivity and specificity of SAAG.
\end{abstract}

Results: The mean value of SAAG in portal-hypertension-related ascites was significantly higher than that in the non-portal-hypertension-related ascites $(21.15 \pm 4.38 \mathrm{~g} / \mathrm{L}$ vs $7.48 \pm 3.64 \mathrm{~g} / \mathrm{L}, \mathrm{P}=0.002)$. The SAAG cut-off value under $12.50 \mathrm{~g} / \mathrm{L}$ predicted portal hypertension ascites with the sensitivity of $99.20 \%$, specificity of $95.10 \%$ and accuracy of $97.65 \%$.

Conclusions: SAAG is useful to distinguish portal-hypertension-related ascites and non-portal-hypertension-related ascites, and $12.50 \mathrm{~g} / \mathrm{L}$ might present as a more reasonable threshold in Chinese ascitic patients.

Virtual slides: The virtual slide(s) for this article can be found here: http://www.diagnosticpathology.diagnomx.eu/vs/ 1602582638991860.

Keywords: Ascites, Cirrhosis, Portal hypertension, SAAG

\section{Introduction}

Ascites is a common manifestation of advanced liver disease. Besides, it can also occur in individuals with extrahepatic diseases such as abdominal malignancy, tuberculosis, and autoimmune diseases. Traditionally, ascites is classified as being either transudative or exudative based on the ascitic fluid total protein (AFTP) concentration [1], the ratio of ascitic fluid protein concentration to serum total protein concentration or lactic dehydrogenase (LDH) [2]. However, the serum ascites albumin gradient (SAAG), defined as the serum albumin concentration minus the ascitic fluid albumin concentration, has been proposed as a physiologically based alternative in the classification of

\footnotetext{
* Correspondence: weifenxie@medmail.com.cn

${ }^{\dagger}$ Equal contributors

Department of Gastroenterology, Shanghai Changzheng Hospital,

Second Military Medical University, Fengyang Road, Shanghai 200003, China
}

ascites in the past 20 years [3-5]. Hoefs [6] first introduces the SAAG and reports that SAAG can reflect the portal vein pressure and improve the accuracy of ascites identification. Thereafter, several investigators also demonstrate that the superiority of SAAG in distinguishing portal hypertensive ascites (SAAG > $11 \mathrm{~g} / \mathrm{L}$ ) and non-portal hypertensive ascites $(\mathrm{SAAG}<11 \mathrm{~g} / \mathrm{L})[6-9]$. Thus, SAAG $11 \mathrm{~g} / \mathrm{L}$ has been considered as a reasonable threshold in clinical practice.

However, there are also some controversies for SAAG [10-12]. In 2002, Goran et al. [13] revise the threshold of SAAG and find that when using the cut-off value of $11 \mathrm{~g} / \mathrm{L}$, the diagnostic sensitivity is $97.56 \%$ and specificity is $46.34 \%$, while using $15.86 \mathrm{~g} / \mathrm{L}$, the sensitivity and specificity could reach the maximum. According to Starling, SAAG is the best indicator of portal hypertension to distinguish nonportal hypertensive and portal hypertensive ascites [14]. However, the best threshold may call further research, the 
primary study reporting $11 \mathrm{~g} / \mathrm{L}$ only included the ascites due to cirrhosis and tumor, except tuberculosis. In fact, tuberculous ascites are also frequently seen in clinical practice. Cirrhosis is mainly caused by alcohol abuse in Western countries, while in China by Hepatitis B virus infection. Besides, China is also an epidemic area for tuberculosis. To date, the SAAG in Chinese patients with ascites has not been evaluated yet. Hence, this study aimed to define a new cut-off value of SAAG with maximal sensitivity and specificity in Chinese patients with ascites.

\section{Material and methods Patients}

Adult patients with ascites admitted to the Shanghai Changzheng Hospital from Jan 2004 to Jun 2010 were retrospectively analyzed. The diagnostic criteria for cirrhotic ascites are mainly based on clinical manifestations, radiological features and esophageal-gastric varicosis, or histopathology, excluding spontaneous bacterial peritonitis (SBP), malignancy and tuberculosis. Malignant ascites was diagnosed when the results of ascitic fluid cytologic study or peritoneal biopsy was positive. The diagnosis of tuberculous peritonitis required ascitic acid-fast stain or mycobacterial growth in a culture of ascites or peritoneal biopsy with or without histologically proven granulomatous peritonitis, and without tuberculous pericarditis. Serum and ascites fluid were obtained (maximum interval 24 hours) and were tested for albumin concentration and other related parameters, the albumin concentration was detected by chemical method using a commercial kit (P800, Roche), other parameters included ascite routine, protein, tumor marker, cast-off cells, ADA. The patients with unknown origin of ascites or without data of SAAG were excluded. We used cirrhotic ascites as Portalhypertension-related (PHT) ascites, and malignant or tuberculous ascites as Non-portal-hypertension-related (NON-PHT) ascites.

\section{Statistical analysis}

Continuous variables were tested for normal distribution and expressed as mean \pm standard deviation (SD) and analyzed by Student's $t$ test. Rates were analyzed by Chisquare test. ROC curve was used to assess the diagnostic value of SAAG. The statistical analysis was performed using SPSS 17.0 (SPSS Inc., Chicago, IL, USA) and P $<0.05$ was considered statistically significant.

\section{Results}

\section{Patient characteristics}

A total of 213 patients diagnosed with ascites were included in this study. The baseline characteristic is shown in (Table 1). The clinical findings of the patients
Table 1 Baseline characteristics of the patients with ascites

\begin{tabular}{lc}
\hline Male : female & $116: 97$ \\
Mean age(y) & $56.82 \pm 14.69$ \\
Cirrhoticascites & 132 \\
HepatitisB & 82 \\
HepatitisC & 1 \\
Schistosomiasis & 5 \\
Alcoholic cirrhosis & 15 \\
Primary biliary cirrhosis & 12 \\
Cryptogeniccirrhosis & 17 \\
NON-PHT ascites & 81 \\
Malignantascites & 54 \\
Gastrointestinal cancer & 28 \\
Pancreatobiliary cancer & 12 \\
Gynecological cancer & 5 \\
Other cancers & \\
Unknown origin" & 4 \\
Tuberculous ascites & 5 \\
\hline
\end{tabular}

* Hepatocellular cancer excluded.

" The unknown origin herein means the ascites were caused by malignant tumor, while we failed to determine the primary site of the tumor after routine examination.

with PTH group and NON-PTH group were similar with respect to age and sex ratio.

\section{SAAG analysis}

The mean SAAG level of all patients involved was $15.95 \pm$ $7.82 \mathrm{~g} / \mathrm{L}$. The mean level of SAAG in the PHT group (cirrhotic ascites) was significantly higher than that in the NON-PHT group (malignant and tuberculous ascites) $(21.15 \pm 4.38 \mathrm{~g} / \mathrm{L} v s 7.48 \pm 3.64 \mathrm{~g} / \mathrm{L}, P=0.002)$. Besides, the SAAG levels of the patients with malignant or tuberculous ascites were both significantly lower than that of patients with cirrhotic ascites (Table 2). In the PHT group, all patients had a SAAG of $11 \mathrm{~g} / \mathrm{L}$ or greater. While in the NON-PHT group, 12 patients had a SAAG of $11 \mathrm{~g} / \mathrm{L}$ or higher, and 69 patients had a SAAG less than $11 \mathrm{~g} / \mathrm{L}$ (Figure 1).

\section{ROC curve}

The ROC curve of SAAG is shown in Figure 2 (Figure 2). The area under the curve was 0.987 , and the SAAG cut-

Table 2 SAAG levels of the patients with ascites

\begin{tabular}{ll}
\hline Cause of ascites & SAAG (g/L) \\
\hline Cirrhotic ascites & $21.15 \pm 4.38$ \\
Malignant ascites & $8.48 \pm 3.68^{*}$ \\
Tuberculous ascites & $5.48 \pm 2.64^{*}$
\end{tabular}

${ }^{*} P<0.05$, compared with cirrhotic ascites. 


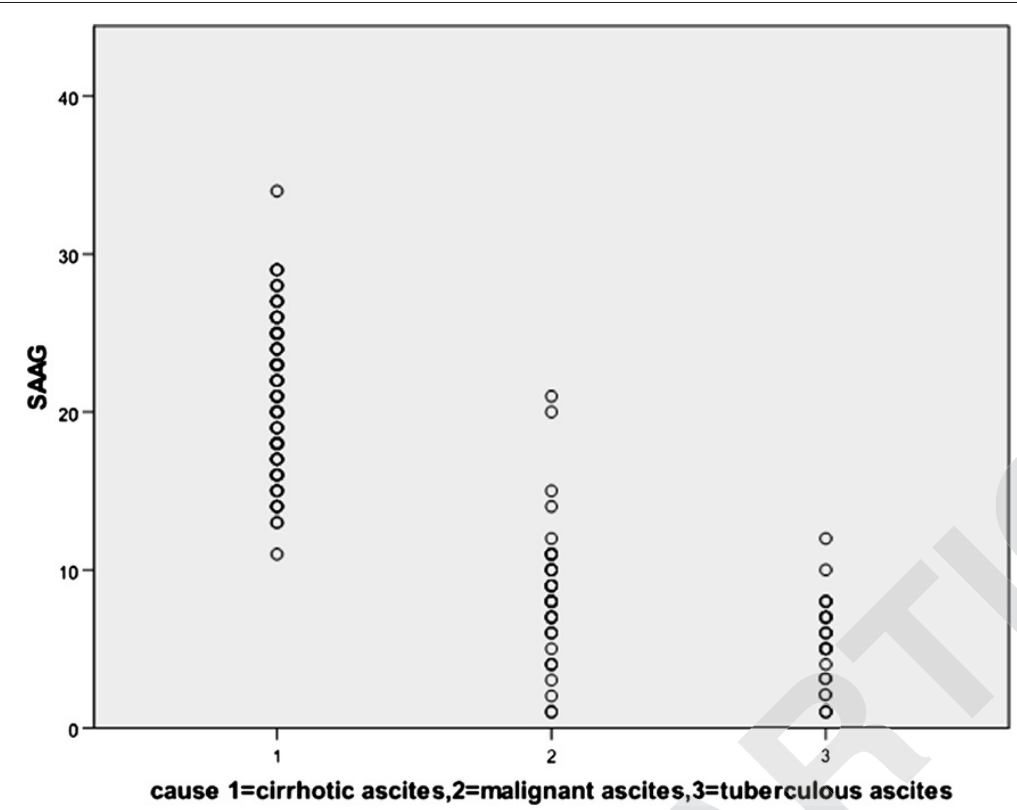

Figure 1 The scatter of SAAG in classifying samples. In the PHT group, all patients had a SAAG of $11 \mathrm{~g} / \mathrm{L}$ or greater. While in the NON-PHT group, 12 patients had a SAAG of $11 \mathrm{~g} / \mathrm{L}$ or higher, and 69 patients had a SAAG less than $11 \mathrm{~g} / \mathrm{L}$.

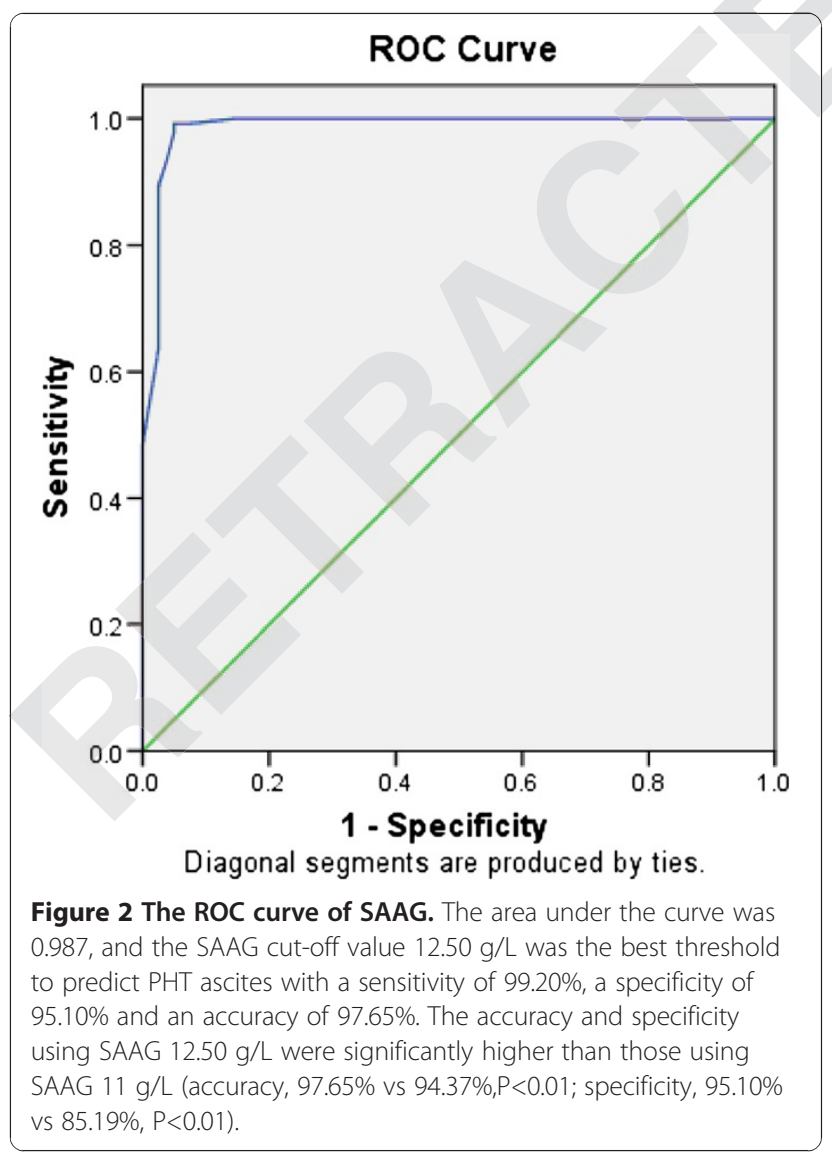

off value $12.50 \mathrm{~g} / \mathrm{L}$ was the best threshold to predict PHT ascites with a sensitivity of $99.20 \%$, a specificity of $95.10 \%$ and an accuracy of $97.65 \%$. When using the SAAG cut-off value $11 \mathrm{~g} / \mathrm{L}$, its sensitivity and specificity were $100.00 \%$ and $85.19 \%$ with an accuracy of $94.37 \%$. The accuracy and specificity using SAAG $12.50 \mathrm{~g} / \mathrm{L}$ were significantly higher than those using SAAG $11 \mathrm{~g} / \mathrm{L}$ (accuracy, $97.65 \%$ vs $94.37 \%, P<0.01$; specificity, $95.10 \%$ vs $85.19 \%, P<0.01)$.

\section{Discussion}

Starling [14] recognizes that the protein content of edema fluid is a reflection of its osmotic pressure and that the osmotic pressure gradient between blood and interstitial fluid is a direct function of the corresponding capillary hydrostatic pressure gradient. According to his concept, the protein concentration gradient between serum and ascites reflects the portal pressure. Hoefs [6] first reports a liner correlation between the SAAG and portal venous pressure in 56 patients with chronic liver disease. More recently, this relationship is also confirmed by Rector and Reynolds [8], who report an excellent correlation between the SAAG and portal pressure. Using AFTP to distinguish exudate and transudate is influenced by serum protein concentration as well as portal pressure. In contrast, the SAAG correlates directly with only one physiologic factor, the portal pressure [6]. Portal pressure keeps stable, and therefore there is no or only minor change of SAAG despite diuresis or therapeutic paracentesis. Hence, it is possible to understand why the SAAG $11 \mathrm{~g} / \mathrm{L}$ has been widely used to differentiate PHT 
and NON-PHT ascites. However, Kajani et al. [15] report that when using the value of SAAG $11 \mathrm{~g} / \mathrm{L}$ for differentiating PHT and NON-PHT ascites, the accuracy is only 87.5\%. In addition, SAAG corrected with serum globulin level could also promote the accuracy to determine portal hypertension [16].

Cirrhosis, cancer and tuberculosis are the most common causes of ascites. As mentioned above, most studies about SAAG are performed in patients with cirrhotic or malignant ascites. However, its utility in tuberculous ascites has not been assessed yet. Therefore, our study involved 27 patients with tuberculous ascites. In this analysis, all the patients with cirrhotic ascites had SAAG of $11 \mathrm{~g} / \mathrm{L}$ or greater, which was rather similar to the study by Shakil et al. [17]. In contrast to the study by Kajani et al. [15], the causes of cirrhosis did not appear to affect SAAG. The albumin gradient in 83 patients with viral-hepatitis-related cirrhosis $(21.28 \pm 4.22 \mathrm{~g} / \mathrm{L})$ was very near to that in the 49 patients with non-viralhepatitis-related cirrhosis $(20.94 \pm 4.67 \mathrm{~g} / \mathrm{L})$. In addition, the SAAG in 117 patients with nonalcoholic liver disease was not different from that in the 15 patients with alcoholic liver disease $(21.26 \pm 4.41 \mathrm{~g} / \mathrm{L}$ vs $20.27 \pm 4.17 \mathrm{~g} / \mathrm{L})$.

With regard to the discrimination between malignant and nonmalignant ascites, Pare et al. [7] report that SAAG less than $11 \mathrm{~g} / \mathrm{L}$ is an excellent criterion for the diagnosis of malignant origin of ascites. Similar observations have also been made by Mauer et al. [5]. Based on the present experience, it appears that the criterion of SAAG less than $11 \mathrm{~g} / \mathrm{L}$ for the distinction between malignant and nonmalignant ascites may be less specific than previously thought. In the present study, a SAAG less than $11 \mathrm{~g} / \mathrm{L}$ was seen in only 43 of 54 patients with malignant ascites without metastatic liver involvement. Similarly, the gradient in the patients with malignant ascites also did not differ from the gradient in the patients with tuberculous ascites. It suggests that SAAG cannot further distinguish malignant ascites from tuberculous ascites.

Runyon et al. [9] report a very high accuracy of $96.7 \%$ for SAAG of $11 \mathrm{~g} / \mathrm{L}$ based on 901 samples. In our study, when using SAAG $11 \mathrm{~g} / \mathrm{L}$, its accuracy was $94.37 \%$, which was slightly lower than $96.7 \%$, while the specificity was only $85.19 \%$. This may be due to the different ascitic etiology between western and eastern countries. The threshold $11 \mathrm{~g} / \mathrm{L}$ is based mainly on the prevalence of alcoholic cirrhosis in Western countries. In China, cirrhosis is mostly caused by HBV infection. Furthermore, the previous evaluation of diagnostic tests often uses sensitivity, specificity and accuracy, which often depend on the prevalence of study population. In fact, the ascitic prevalence is different in western and eastern countries. Moreover, the receiver operating characteristic (ROC) curve is currently recognized as the best way to measure the diagnostic information and decision-making. The cut-off value obtained by ROC curve has greater accuracy and clinical utility $[18,19]$. Our research achieved a new value of SAAG of $12.5 \mathrm{~g} / \mathrm{L}$ by ROC curve. Compared with the previous SAAG of $11 \mathrm{~g} / \mathrm{L}$, the new SAAG had higher accuracy and specificity to distinguish PHT and NON-PHT ascites.

Based upon the data herein presented, we conclude that SAAG is useful to distinguish PHT and NON-PHT ascites, and $12.5 \mathrm{~g} / \mathrm{L}$ might present as a more reasonable threshold in Chinese ascitic patients. However, further study is still needed to be done using larger samples.

\section{Competing interest}

The authors declare that they have no competing interests.

\section{Authors' contributions}

CFJ, BS and JS: Designed the experiments, and acquired and analyzed the data. ZLY and WFX: Designed the experiments and drafted the manuscript

All authors read and approved the final manuscript.

Received: 11 May 2013 Accepted: 30 July 2013

Published: 23 August 2013

\section{References}

1. Paddock FK: The diagnostic significance of serous fluids in disease. N Engl J Med 1940, 223:1010-1015.

2. Light RW, Macgregor MI, Luchsinger PC, Ball WC: Pleural effusions: the diagnostic separation of transudates and exudates. Ann Intern Med 1972, 77:507-513.

3. McHutchison J: Differential diagnosis of ascites. Semin Liv Dis 1997 , 17(3):191-202.

4. Karoo R, Lloyd T, Garcea G, Redway H, Robertson G: How valuable is ascitic cytology in the detection and management of malignancy? Postgrad Med J 2003, 79:292-294.

5. Mauer K, Manzione NC: Usefulness of serum-ascites albumin difference in separating transudative from exudative ascites. Dig Dis Sci 1988, 33:1208-1212

6. Hoefs J: Serum protein concentration and portal pressure determine the ascitic fluid protein concentration in patients with chronic liver disease. J Lab Clin Med 1983, 102:260.

7. Pare P, Talbot J, Hoefs J: Serum-ascites albumin concentration gradient: a physiologic approach to the differential diagnosis of ascites. Gastroenterology 1983, 85:240.

8. Rector WG, Reynolds TB: Superiority of the serum-ascites albumin difference over the ascites total protein concentration in separation of "transudative" and "exudative" ascites. Am J Med 1984, 77:83-85.

9. Runyon BA, Montano AA, Akriviadis EA, Antillon MR, Irving MA, McHutchison JG: The serum-ascites albumin gradient is superior to the exudate-transudate concept in the differential diagnosis of ascites. Ann Intern Med 1992, 117:215-220.

10. Torres E, Barros P, Calmet F: Correlation between serum-ascites albumin concentration gradient and endoscopic parameters of portal hypertension. Am J Gastroenterol 1998, 93:2172-2178.

11. Das BB, Purohit A, Acharya U, Treskova E: Serum-ascites albumin gradient: a predictor of esophageal varices with ascites. Indian J Pediatr 2001, 68:511-514.

12. Lee CM, Changchien CS, Shyu WC, Liaw YF: Serum-ascites albumin concentration gradient and ascites fibronectin in the diagnosis of malignant ascites. Cancer 1992, 70:2057-2060.

13. Bjelaković G, Nagorni A, Stamenković I, Benedeto-Stojanov D, Brzački V, Raičević S, Radovanović B, Bjelaković M, Katić V, Živković V: The value of serum-ascites albumin gradient in differential diagnosis of ascites and the proposal for the new cut-off value. Acta Facultatis Medicae Naissensis 2003, 20:209-212.

14. Starling EH: On the absorption of fluids from the connective tissue spaces. J Physiol 1896, 19:312-326. 
15. Kajani MA, Yoo YK, Alexander JA, Gavaler JS, Stauber RE, Dindzans VJ, Van Thiel DH: Serum-ascites albumin gradients in nonalcoholic liver disease. Dig Dis Sci 1990, 35:33-37.

16. Hoefs JC: Globulin correction of the albumin gradient: correlation with measured serum to ascites colloid osmotic pressure gradients. Hepatology 1992, 16:396-403.

17. Obaid Shakil A, Korula J, Kanel GC, Murray NG, Reynolds TB: Diagnostic features of tuberculous peritonitis in the absence and presence of chronic liver disease: a case control study. Am J Med 1996, 100:179-185.

18. Wixted JT, Squire LR: Constructing receiver operating characteristics (ROCs) with experimental animals: cautionary notes. Learn Mem 2008, 15:687-690.

19. Johnson M, Chipp C, Brems C, Neal D: Receiver operating characteristics for the brief symptom inventory depression, paranoid ideation, and psychoticism scales in a large sample of clinical inpatients. Psychol Rep 2008, 102:695.

doi:10.1186/1746-1596-8-143

Cite this article as: Jiang et al.: New proposal for the serum ascites albumin gradient cut-off value in Chinese ascitic patients. Diagnostic Pathology 2013 8:143.

\section{Submit your next manuscript to BioMed Central and take full advantage of:}

- Convenient online submission

- Thorough peer review

- No space constraints or color figure charges

- Immediate publication on acceptance

- Inclusion in PubMed, CAS, Scopus and Google Scholar

- Research which is freely available for redistribution 